\title{
How do organizations implement downsizing? - An Australian and New Zealand study
}

\author{
Franco Gandolfi \\ Cedarville University \\ E-Mail: fgandolfi@cedarville.edu
}

\begin{abstract}
The Australian and New Zealand banking industries have been cutting their workforces steadily since the mid-1990s. With further rounds of workforce downsizing predicted, it was of considerable interest and importance to examine the implementation strategies that large Australian and New Zealand banks have adopted in their latest downsizing endeavors. This study has revealed three major findings. First, Australian banks tended to primarily adopt workforce reduction strategies, whereas New Zealand banks employed a mixture of organization redesign strategies, workforce reduction strategies, and systemic strategies. Second, Australian banks were perceived to have considerable depth in their downsizing, whereas New Zealand banks had more breadth in their overall strategies. Third, Australian banks favored to adopt reorientation approaches, whereas New Zealand banks were more inclined to embrace reinforcement (convergence) approaches. It remains unclear as to why large Australian and New Zealand banks have diverged in their approaches and strategies to downsizing and in their differing selection of available implementation strategies. Government interference, executive remuneration, industrial relations demands, competitive national and international market pressures, and the downsizing history of individual industries and organizations, on the one hand, and differences in national cultures and cultural values on the other, may have influenced the adoption of downsizing implementation strategies. At the same time, it has also been shown that downsizing has engendered negative financial, organizational, and social consequences in both Australia and New Zealand.
\end{abstract}

Key words: Downsizing, implementation strategies, banks

\section{INTRODUCTION}

Since the early to mid-1980s, organizational downsizing has become an omnipresent feature of a multitude of corporations and governmental agencies throughout the industrialized world (Littler, 1998). The prime catalyst for the majority of downsizing activities is the objective of a reduction of costs (Cascio, 1993), an increase of an organization's levels of efficiency, effectiveness, productivity (Gandolfi, 2002), and competitiveness (Cameron, 1994), and thus an organization's overall performance (Thornhill \& Saunders, 1998). Therefore, the major raison d'être of any downsizing endeavor is to make an organization more competitive compared to its rivals (De Vries \& Balazs, 1997). Empirical and anecdotal evidence suggest that the financial, 
organizational, and social consequences of downsizing are largely negative (Morris, Cascio, \& Young, 1999). Littler, Dunford, Bramble, and Hede (1997) assert that the after-effects of a downsizing affect the entire organization and its workforce in a most profound manner. There is also mounting evidence that suggests that organizations commenced downsizing efforts with inadequate plans, policies, and programs in place (Appelbaum, Delage, Labibb, \& Gault, 1997), were ill-prepared for the aftermath of downsizing (Gandolfi, 2001), and severely neglected the employees that remained within the organizational system (Doherty \& Horsted, 1995). The downsizing of organizational workforces is not a business phenomenon of the recent past. Rather, it has maintained and even increased its popularity and pervasiveness as a deliberate restructuring strategy in all industries (Morris et al., 1999), across the world (Dolan, Belout, \& Balkin, 2000), and into the new millennium (Baruch \& Hind, 2000; Lamsa \& Takala, 2000; Gandolfi, 2003). Given the apparent absence of positive outcomes from downsizing (Cascio, 1993), the frequency of negative implications following downsizing (Morris et al., 1999), the ongoing popularity of downsizing (Harrison, 2000; Gandolfi, 2003), and the assertion of scholars that downsizing is still regarded as an understudied business phenomenon (Luthans \& Sommer, 1999), this study aims to examine the adopted downsizing implementation strategies of large banks in Australia and New Zealand.

The structure of this research paper is threefold. First, it reviews the literature on downsizing implementation strategies and presents the main research question. Second, it determines the implementation strategies that large Australian and New Zealand banks adopted in their last round of downsizing by means of the case-study methodology. Last, it analyzes and discusses the empirical findings derived from in-depth interviews.

\section{DOWNSIZING IMPLEMENTATION STRATEGIES}

The downsizing literature reveals that a number of distinct implementation strategies have been identified. Cameron, Freeman, and Mishra $(1991,1993)$ have conducted one of the most extensive and systematic studies of corporate workforce downsizing and reported three major findings regarding downsizing implementation strategies. First and foremost, they identified and differentiated between three distinct types of downsizing implementation strategies. That is, a workforce reduction strategy, an organization redesign strategy, and a systemic strategy. An overview of the downsizing implementation strategies is exhibited in Table 1.

Table 1 Downsizing implementation strategies

\begin{tabular}{|l|l|l|l|}
\hline & $\begin{array}{l}\text { Workforce reduction } \\
\text { strategy }\end{array}$ & $\begin{array}{l}\text { Organization redesign } \\
\text { strategy }\end{array}$ & Systemic strategy \\
\hline Focus & Workers & Jobs and units & Culture \\
\hline Target & People & Work & Status quo processes \\
\hline Implementation time & Quick & Moderate & Extended \\
\hline Temporal target & Short-term payoff & Moderate-term payoff & Long-term payoff \\
\hline Inhibits & $\begin{array}{l}\text { Long-term } \\
\text { adaptability }\end{array}$ & Quick payback & Short-term cost savings \\
\hline
\end{tabular}




\begin{tabular}{|c|c|c|c|}
\hline & $\begin{array}{l}\text { Workforce reduction } \\
\text { strategy }\end{array}$ & $\begin{array}{l}\text { Organization redesign } \\
\text { strategy }\end{array}$ & Systemic strategy \\
\hline Examples & $\begin{array}{l}\text { - Natural attrition } \\
\text { - Hiring freeze } \\
\text {-Early retirement } \\
\text {-Buyout packages } \\
\text {-Layoffs } \\
\text {-Retrenchments }\end{array}$ & $\begin{array}{l}\text {-Abolition of functions } \\
\text {-Merging of units } \\
\text {-Job Redesign } \\
\text {-De-layering } \\
\text {-Reducing overall work } \\
\text { hours }\end{array}$ & $\begin{array}{l}\text {-Staff involvement } \\
\text {-Simplification of } \\
\text { processes } \\
\text { •Bottom-up change } \\
\text {-Continuous } \\
\text { improvement }\end{array}$ \\
\hline
\end{tabular}

Source: adapted from Cameron et al. (1991, 1993)

The workforce reduction strategy, often referred to as the "layoff strategy" (Ryan \& Macky, 1998: 38), concentrates primarily upon the elimination of headcount and the reduction of the overall number of employees. It encompasses activities, such as layoffs, retrenchments, natural attritions, early retirements, hiring freezes, golden parachutes, and buyout packages (Cameron et al., 1991; 1993). This strategy is frequently implemented in a reactive manner as a cost-cutting measure and may serve as a short-term response to declining profits (Ryan \& Macky, 1998). According to Cameron (1994), such "grenade-type” (p 198) approaches to downsizing are rarely successful and tend to be negative in their consequences. The organization redesign strategy focuses predominantly upon the elimination of work, rather than reducing the number of employees (Luthans \& Sommer, 1999). It encompasses activities, such as abolishing functions, eliminating hierarchical levels (de-layering), groups, divisions, products, redesigning tasks, consolidating and merging units, and reducing overall work hours. Organization redesign strategies are commonly regarded as being difficult to implement quickly as this requires some advanced analysis of the areas concerned (Cameron et al., 1991). The systemic strategy is fundamentally different from the former two strategies in the sense that it appears to embrace a more holistic view of organizational change. Thus, downsizing ought to embrace all dimensions and aspects of the organization, including suppliers, customer relations, production methods, design processes, and inventories (Cameron, 1994). Systemic strategy focuses primarily upon changing the organization's intrinsic culture and the attitudes and values of its employees (Luthans \& Sommer, 1999). Hence, downsizing is viewed as "a way of life” (Filipowski, 1993: 1) and an on-going, continuous, and incremental process (Cameron et al., 1991). Within this framework, employees are not seen as the primary target of downsizing, but considered to be resources in an attempt to produce and incorporate downsizing ideas (Cameron, 1994).

Cameron and his associates have also compartmentalized downsizing on the basis of the depth and breadth of available downsizing strategies. This is depicted in Table 2. 
Table 2 Depth and breadth of downsizing

\begin{tabular}{|c|c|c|c|}
\hline Increasing depth & Increasing breadth & & \\
\hline \multirow[b]{2}{*}{ 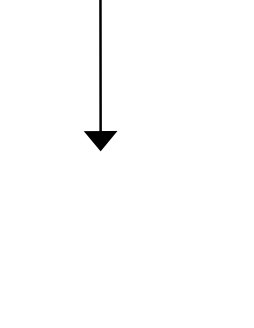 } & $\begin{array}{c}\text { Workforce reduction } \\
\text { strategy }\end{array}$ & $\begin{array}{c}\text { Organization redesign } \\
\text { strategy }\end{array}$ & Systemic strategy \\
\hline & $\begin{array}{l}\text {-Natural attrition } \\
\text {-Layoffs/retrenchments } \\
\text {-Early retirements } \\
\text {-Buyout packages }\end{array}$ & $\begin{array}{l}\text {-Layer elimination } \\
\text {-Unit combination } \\
\text {-Product removal } \\
\text {-Process rearrangement } \\
\end{array}$ & $\begin{array}{l}\text {-System analysis } \\
\text { •Culture change } \\
\text { •Bottom design }\end{array}$ \\
\hline
\end{tabular}

Source: adapted from Cameron et al. (1991, 1993)

According to Cameron et al. (1991), organizations that incorporate a greater number of actions of the same category of implementation have more depth in their overall downsizing strategy. Conversely, organizations that employ a variety of strategy types have more breadth in their strategy. The results of a four-year study of 30 American organizations that had engaged in downsizing activities have disclosed that organizations were generally more likely to have depth rather than breadth in their overall strategy. This revelation can be attributed to the fact that most downsized organizations embarked upon workforce reduction alternatives rather than employing a multiplicity of downsizing strategies (Cameron, 1994).

Two archetypal approaches to downsizing have emerged - reinforcement and reorientation. These approaches were originally developed and empirically tested by Freeman (1994), who had labeled these concepts "convergence" and "reorientation" (p 214). The approaches of reinforcement and reorientation are built upon differing models of organizational change. The concept of reinforcement (convergence) embraces the notion of an evolutionary, incremental, and gradual change model. As a consequence, reinforced or converged downsizing would be implemented on a smaller scale and as part of a process aimed at reinforcing an organization's mission, strategy, systems, and structure (Ryan \& Macky, 1998). The concept of reorientation, in contrast, encompasses the notion of a revolutionary, metamorphic, and discontinuous change model. Thus, reoriented downsizing would be implemented on a larger scale, with major redefinitions of an organization's mission, strategy, and structure (Cameron et al., 1993). The two contrasting approaches are depicted in Table 3.

Having reviewed the existing downsizing implementation strategies, the underlying research question of this study was to examine what main downsizing strategy or strategies large Australian and New Zealand banks implemented in their last round of downsizing. 
Table 3 Reinforcement and reorientation approaches

\begin{tabular}{|l|l|}
\hline \multicolumn{1}{|c|}{ Reinforcement (convergence) approach } & \multicolumn{1}{c|}{ Reorientation approach } \\
\hline$\bullet$ Incremental downsizing and redesign & $\bullet$ Discontinuous downsizing and redesign \\
\hline$\bullet$ Lower-level, less radical approaches & $\bullet$ Higher-level, more radical approaches \\
\hline $\begin{array}{l}\bullet \text { Stability in management, technology, and } \\
\text { systems }\end{array}$ & $\bullet$ Change in management, technology, and systems \\
\hline$\bullet$ Changes in work, instead of structure & $\bullet$ Changes in structure, instead of work \\
\hline$\bullet$ Reinforces mission and strategy & $\bullet$ Redesign mission and strategy \\
\hline$\bullet$ Focus upon doing things better & $\bullet$ Focus upon doing different things \\
\hline$\bullet$ Emphasis upon efficiency criteria & $\bullet$ Emphasis upon effectiveness criteria \\
\hline$\bullet$ Downsizing precedes redesign & $\bullet$ Redesign precedes downsizing \\
\hline
\end{tabular}

Source: adapted from Cameron et al. (1993)

\section{LARGE BANKS IN AUSTRALIA AND NEW ZEALAND}

Downsizing has occurred throughout the industrialized world (Ryan \& Macky, 1998), affected blue and white collar workers (Littler et al., 1997), targeted lower-level workers, professionals, middle managers, and higher-level workers (Littler, 1998), and permeated all industries (Morris et al., 1999). The banking sector has been particularly affected by the deregulation of the finance industry in both Australia and New Zealand. Some of the more notable repercussions have been workforce layoffs, redundancies, retrenchments, early retirements, buyout packages, golden handshakes, and branch closures. In Australia, for example, the size of the overall workforce in the finance industry has been rapidly declining since the early 1990s (Finance Sector Union, 2002: 4). According to the Australian Bureau of Statistics (ABS) (1998), the workforce of the Australian finance industry declined by $8.8 \%$ between 1991 and 1996. This development was exacerbated by the fact that the implementation of downsizing in the Australian finance industry has proceeded and further rationalization activities have been predicted (Finance Sector Union, 2002: 4). In a similar vein, Harrison (2000) opines that the downsizing of Australian banks is not a phenomenon of the past and predicts that downsizing will remain a principal strategic managerial tool for the major banking institutions (Harrison, 2000).

The New Zealand banking industry has also undergone significant structural, political, and technological changes since the commencement of the deregulation of the finance industry in the late 1980s. In line with developments in Australia, the workforce of the New Zealand banking industry has been steadily declining since the mid-1990s. Anecdotal evidence suggests that all major banks have had at least one round of workforce downsizing since the late 1990s and most large banks are currently considering further reductions in workforce. The author of this report was actively involved in the execution and implementation of two separate downsizing activities in large New Zealand banks in 2001 and 2002. A relatively recent report from a New Zealand governmental agency revealed that up to two thirds of all finance jobs could potentially disappear by the year 2015 due to projected restructuring activities and consolidations (New Zealand Banking Review, 2003). 
Having surveyed the literature and examined some of the recent developments of workforce levels in the Australian and New Zealand banking industries, the fundamental question arises as to whether there may be differences in the way banks execute downsizing. In other words, do Australian and New Zealand banks differ in their adoption of downsizing strategies and in their depth and breadth of downsizing? Do contextual and cultural differences result in differing downsizing strategies? Are organizations in certain cultural environments more likely to favor specific downsizing strategies? Are differences in national cultures reflected in organizational decisions about downsizing? Hitherto, no comparative studies on possible similarities and dissimilarities between two different countries and their downsizing strategies have been documented. Analyzing the Australian and New Zealand national cultures and determining the cultural similarities and divergences in greater detail is beyond the scope of this paper. However, given the progression of deregulation, the composition and national importance of the banking sectors, and the geopolitical interdependence of both countries, it was expected that the findings would depict a consistent and convergent picture.

\section{CASE STUDY METHODOLOGY}

Academic research on downsizing should adopt an inductive theory-building rather than a deductive theory-testing approach (Cameron et al., 1993; Ryan \& Macky, 1998). This judgment corresponds with Littler (1998), Morris et al. (1999), and Dolan et al. (2000). As a consequence, this study has employed the case study methodology. Case study research is essentially a form of "empirical inquiry" (Yin, 1994: 23). According to Yin (2003), the case study method focuses upon a phenomenon within its real-life context by obtaining data from a multitude of sources in order to comprehensively investigate and analyze the phenomenon in-depth. Thus, the case study method has the capacity to generate theory (Yin, 2003). The selection of cases in qualitative case study research is purposeful (Perry, 1998) and involves the use of replication rather than sampling logic (Eisenhardt, 1989; Yin, 1994; Carson, Gilmore, Gronhaug, \& Perry, 2001). Furthermore, the selection of individual cases depends largely upon the conceptual framework developed in the literature review and prior theory (Perry, 1998). The ultimate underlying principle of the selection procedure is selecting "information rich cases" (Patton, 1990: 181). According to Stake (1994), the importance of information richness (Patton, 1990) exceeds the issue of representativeness. This study has purposefully selected eight study cases - the four largest Australian and the four largest New Zealand banks. The research has exclusively involved large banks, as measured by the total number of employees (Robbins, 1983). The eight banks are considered the key players in their respective industries and countries. The decision to involve large organizations was due to Keller's (1998) observation that "it is the large companies that appear to have been the prime targets of organizational downsizing” (Keller, 1998: 324).

A considerable number of in-depth, face-to-face interviews and teleconferences with senior, middle, and operational managers of the eight study cases were conducted between October 2003 and March 2004. The administrative titles of the key informants included Chief Executive Officer (CEO), Chief Operations Officer (COO), Chief Knowledge Officer (CKO), Director HR, Director L\&D, Manager L\&D, and HR Manager. The distinction between executive, middle, and lower-level management was critical to the success of the study and satisfied the requirement of conducting interviews at different hierarchical levels within all case study organizations (Perry, 
1998; Carson et al., 2001). The qualifying criteria for all involved participants were (1) the status of being a downsizing 'survivor' (Noer, 1993) and (2) the status of being a downsizing 'driver' (Dolan et al., 2000). In other words, participants needed to have served the downsized organization prior to, during, and after the downsizing and must have been actively involved in the actual planning, development, and execution of the downsizing endeavor.

There was an underlying expectation that participants would provide information that would in turn have the capacity to build theory. Thus, participants were seen as "informants" (Bogdan \& Biklen, 1998: 32) rather than mere "respondents" (Yin, 1994: 84). All managers were interviewed only once over the six-month period with each interview lasting from one to one and a half hours. The interviews were focused (Adams \& Schvaneveldt, 1991) in nature. This allowed the interviewer to probe far beyond the answers to the prepared and standardized questions (Berg, 1989). With the consent of the participating organizations and individual managers, each interview was taped and meticulously transcribed and documented. The interview transcripts constituted the main raw material (Silverman, 1997), and provided "highly detailed and publicly accessible representations of social interaction” (Silverman, 1997: 203). A total of thirty-six participants across all eight study cases were interviewed - twelve executive managers, twelve middle managers, and twelve operational managers. The overall figure was consistent with the case study literature that suggests the number of conducted interviews to be in the range of 20 to 50 participants (Larsson, 1993; Perry, 1998).

\section{RESULTS AND DISCUSSION}

This case study ascertained the downsizing implementation strategies of large Australian and New Zealand banks. It also sought to determine patterns, consistencies, and anomalies in regard to the implemented downsizing strategies among and between the main banks. Three key findings have emerged. First, the study has shown that all participants declared that their respective organization has engaged in workforce downsizing practices since the early days of this millennium. The vast majority of Australians stated that workforce reduction strategies, including workforce layoffs, retrenchments, early retirements, buyout packages, natural attritions, and hiring freezes, were the most commonly utilized downsizing strategies and adopted without restraint in the most recent round of downsizing. A considerable number of participants indicated that layoffs and staff retrenchments were frequently seen as the bank's "first preference". In this sense, participants understood that workforce reduction strategies were likely to have a quick implementation time with short-term payoffs. In contrast, organization redesign strategies, including job redesign, merging of units, abolition of functions, and delayering, were not seen as primary strategies. Rather, these secondary strategies were seen as a direct consequence of the primary downsizing implementation strategies. In other words, in an Australian context, organization redesign strategies were utilized only in response to and as a direct consequence of the adoption of workforce reduction strategies. The systemic strategy, that views downsizing as 'a way of life', was rejected by all Australian managers. Participants perceived systemic strategies to inhibit short-term savings and to only engender long-term payoffs. Thus, systemic strategies were not seen as suitable implementation strategies. 
In stark contrast to Australian banks, New Zealand bank managers perceived organization redesign strategies to be the preferred downsizing implementation strategy. According to the New Zealand participants, the primary focus of any downsizing endeavor should be "work" rather than "people". In other words, the emphasis should lie with the elimination of work rather than reducing the number of employees in the first instance. Participants nominated the redesign of tasks and the consolidation of work, units, products, groups, and divisions as the standard practices in downsizing efforts. However, New Zealand managers stressed that the adoption of organization redesign strategies necessitated a profound level of understanding of the individual operations and tasks and also required some advanced analysis of the targeted areas. Workforce reduction strategies were seen as a "last resort". They were also viewed to inhibit long-term adaptability and perceived to be "extremely disruptive" and "damaging to the image, ethos, and culture of the organization". At the same time, New Zealand managers admitted that a number of workforce reduction strategies, including specific hiring freezes, natural attritions, and limited retrenchments, were embraced in the last round of downsizing. New Zealand participants also stated that even though a systemic strategy per se, with its focus on culture, was not adopted, some distinct elements of a systemic strategy were nevertheless actively being pursued, including, continuous improvement, staff involvement, and bottom-up change.

Second, this research has revealed that there were differences in the breadth and depth of downsizing implementation strategies between Australian and New Zealand banks. Australian bank managers generally resorted to workforce reduction strategies as primary downsizing implementation strategies and largely forfeited the options of organization redesign strategies and systemic strategies. More specifically, all Australian study cases reported the adoption of layoffs, retrenchments, early retirements, natural attritions, hiring freezes, and early buyouts. Moreover, these strategies were utilized by all Australian banks in their last round of downsizing. Thus, Australian banks showed great depth in their downsizing. In stark contrast, New Zealand bank managers tended to embrace a more holistic approach to downsizing and resorted to a broader variety of implementation strategies. According to the participants, downsizing strategies comprised (1) the primary tools of redesigning tasks and consolidating of work, units, products, groups, and divisions, (2) the secondary tools of hiring freezes, natural attritions, early retirements, voluntary redeployments, and voluntary separation packages, and (3) the "last resort" tools of involuntary redeployment, retrenchments, and layoffs. At the same time, participants declared that systemic strategies, such as continuous improvement, bottom-up change, and staff involvement, were also pursued and implemented. Thus, New Zealand banks showed great breadth in their downsizing.

Third, the study has shown that Australians had a tendency to embrace "reorientation" (Cameron et al., 1993) approaches to downsizing, whereas New Zealand bank managers were more likely to adopt "reinforcement" (Cameron et al., 1993) or "convergence" (Freeman, 1994) approaches. More specifically, Australians tended to engage in radical, high-level approaches, in that significant change to mission, strategy, structure, systems, and technology occurred in the last round of downsizing. Participants viewed the approach to change to be "discontinuous". The last round of downsizing was also implemented on a larger scale with major redefinitions. However, New Zealand participants incorporated less radical and lower-level approaches in their last round of downsizing, seeing it as a way to "reinforce mission and strategy" and stability in management, systems, and technology. There also seemed an emphasis upon changes in work 
rather than people. Participants perceived the approach to downsizing to be "incremental" and "gradual". Participating managers stated that the last round of downsizing was implemented on a smaller scale and as part of a continuing process.

An overview of the three main findings in regards to comparative inter-countries downsizing strategies is exhibited in Table 4.

Table 4 Overview of comparative inter-countries downsizing strategies

\begin{tabular}{|c|c|c|}
\hline & Australia & New Zealand \\
\hline Implementation strategies & $\begin{array}{c}\text { Mostly workforce reduction } \\
\text { strategies }\end{array}$ & $\begin{array}{c}\text { Mostly organization redesign } \\
\text { strategies }\end{array}$ \\
\hline $\begin{array}{c}\text { Breadth/Depth in overall } \\
\text { downsizing }\end{array}$ & $\begin{array}{c}\text { More depth in overall } \\
\text { downsizing }\end{array}$ & More breadth in overall downsizing \\
\hline Approach to downsizing & Reorientation approach & Reinforcement approach \\
\hline
\end{tabular}

Source: analysis of field data

\section{CONCLUSION}

This study examined the adopted downsizing implementation strategies of large Australian and New Zealand banks. At the outset of the research, the study reviewed the literature on downsizing implementation strategies and presented the research question. The adoption of the case study methodology enabled the researcher to analyze and determine the implementation strategies adopted by large Australian and New Zealand banks in their last round of downsizing. Following the processes of data gathering, analysis, and interpretation, three major findings emerged. First, Australian banks tended to primarily adopt workforce reduction strategies, whereas New Zealand banks had a mixture of organization redesign strategies, workforce reduction strategies, and systemic strategies. Second, Australian banks were perceived to have considerable depth in their downsizing, whereas New Zealand banks had more breadth in their implementation strategies. Third, Australian banks tended to adopt reorientation approaches, whereas New Zealand banks were more inclined to embrace reinforcement or convergence approaches. Prior to this study, there was little comparative data on downsizing implementation strategies between and among competitors, industries, and countries available. Given the progression of deregulation, the composition and national importance of the banking sectors, and the geographical and geopolitical interdependence of both countries, there was an implicit expectation that the cross-comparison of implementation strategies would show a relatively convergent picture. However, this study has shown that the differences in the adoption of downsizing strategies between Australian and New Zealand banks were considerable. This poses a multitude of questions. For example, do the results show a general pattern? How can the similarities and dissimilarities be specifically explained? How do the results compare to other comparative cross-sectional and cross-cultural studies? In the absence of an established framework and the apparent lack of comparative cross-cultural data, the task of providing a clear conclusion is problematic. It remains unclear as to why large Australian and New Zealand banks have diverged in their approaches and strategies to downsizing and in their differing selection of available implementation strategies. Possible explanations are manifold - government interference, executive remuneration, industrial relations demands, competitive national and international market pressures, and the downsizing history of individual industries and 
organizations, on the one hand, and differences in national cultures and cultural values, on the other, may have influenced the adoption of downsizing implementation strategies. Finally, there is mounting empirical evidence that suggests that downsizing has the propensity to engender negative financial, organizational, and social consequences. A number of studies in both Australia and New Zealand have reported negative after-effects following downsizing. The small sample size in this study limits the generalizability of the findings in that they may not be generalized across Australian and New Zealand banks and across Australian and New Zealand industries. The study also solely focused upon large banking institutions and middle-sized and small-sized banks were not considered for the purpose of this study.

\section{REFERENCES}

Adams, G.R., \& Schvaneveldt, J.D. 1991. Understanding Research Methods $2^{\text {nd }}$ Edition Longman Publishing Group.

Appelbaum, S.H., Delage, C., Labibb, N., \& Gault, G. 1997. The survivor syndrome: aftermath of downsizing. Career Development International, 2 (6).

Australian Bureau of Statistics (ABS). 1998. Employer Training Practices, Australia Commonwealth of Australia.

Baruch, Y., \& Hind, P. 2000. "Survivor syndrome" - a management myth? Journal of Managerial Psychology, 15 (1): 29-45.

Berg, B.L. 1989. Qualitative Research Methods for the Social Sciences. Allyn and Bacon Boston.

Bogdan, R.C., \& Biklen, S.K. 1998 Qualitative Research in Education. $3^{\text {rd }}$ Edition Allyn \& Bacon Boston.

Cameron, K.S. 1994. Strategies for successful organizational downsizing. Human Resource Management, 33 (2): 189-211.

Cameron, K.S., Freeman, S.J., \& Mishra, A.K. 1991. Best practices in white-collar downsizing: managing contradictions. Academy of Management Executive, 5 (3): 57-73.

Cameron, K.S., Freeman, S.J., \& Mishra, A.K. 1993. Downsizing and redesigning organizations in Huber, G \& Glick, W (eds), Organizational Change and Redesign (19-63) New York Oxford University Press.

Carson, D.J., Gilmore, A., Gronhaug, K., \& Perry, C. 2001. Qualitative Marketing Research. Sage Publications.

Cascio, W.F. 1993. Downsizing: What do we know? What have we learned?. Academy of Management Executive, 7 (1): 95-104.

De Vries, M.F.R.K., \& Balazs, K. 1997. The downside of downsizing. Human Relations, 50 (1): 11-50.

Doherty, N., \& Horsted, J. 1995. Helping survivors to stay on board. People Management Personnel Publications Limited, January 12, London.

Dolan, S., Belout, A., \& Balkin, D.B. 2000. Downsizing without downgrading: learning how firms manage their survivors. International Journal of Manpower, 21 (1): 34-46.

Eisenhardt, K.M. 1989. Building theories from case study research. Academy of Management Review, 14 (4): 532-550.

Filipowski, D. 1993 Don’t rush downsizing: plan, plan, plan. Personnel Journal, November 1993 72 (11): 64-76. 
Finance Sector Union. 2002. The Finance Sector: Workforce Report Volume 1. Finance Sector Union of Australia.

Freeman, S.J. 1994. Organizational downsizing as convergence or reorientation: implications for human resource management. Human Resource Management, 33 (2): 213-238.

Gandolfi, F. 2001. How and why should training and development be implemented during the process of organizational downsizing? Thesis for the award of Doctor of Business Administration (DBA) Southern Cross University, Australia.

Gandolfi, F. 2002. Should training and development be implemented during organizational downsizing? A case study. Australia and New Zealand Academy of Management (ANZAM).

Gandolfi, F. 2003. Organizational downsizing: a review of the background, its development, and current status. The Australasian Journal of Business and Social Inquiry, 1 (1).

Harrison, J. 2000 Australian banks return record profits and axe thousands of jobs. World Socialist Web Site Published by the International Committee of the Fourth International (ICFI) pp 1-5.

Keller, M. 1998. Downsizing in the New Zealand banking industry Seminar paper presented to the Roche Consortium. University of Auckland, July 1998.

Larsson, R. 1993. Case survey methodology: qualitative analysis of patterns across case studies. Academy of Management Journal, 36 (6): 1515-1546.

Lamsa, A.M., \& Takala, T. 2000. Downsizing and ethics of personnel dismissals - the case of Finnish managers. Journal of Business Ethics, 23: 389-399.

Littler, C.R. 1998. Downsizing organizations: the dilemmas of change. Human Resources Management Bulletin, CCH Australia Limited, Sydney.

Littler, C.R., Dunford, R., Bramble, T., \& Hede, A. 1997. The dynamics of downsizing in Australia and New Zealand. Asia Pacific Journal of Human Resources, 35 (1): 65-79.

Luthans, B.C., \& Sommer, S.M. 1999. The impact of downsizing on workplace attitudes. Group and Organization Management, 24 (1): 46-70.

Morris, J.R., Cascio, W.F., \& Young, C.E. 1999. Downsizing after all these years: Questions and answers about who did it, how many did it, and who benefited from it. Organizational Dynamics, Winter 1999: 78-87.

New Zealand Banking Revue. 2003. The Magazine for the New Zealander Abroad, 4: August 2003.

Noer, D. 1993. Healing the Wounds: Overcoming the Trauma of Layoffs and Revitalizing Downsized Organizations, Jossey-Bass, San Francisco, CA.

Patton, M.Q. 1990. Qualitative Evaluation and Research Methods, Sage, Newbury Park, California.

Perry, C. 1998. Processes of a case study methodology for postgraduate research in marketing. The New Zealand Journal of Business, 32: 9-10.

Robbins, S.P. 1983. Organization Theory. The Structure and Design of Organizations, PrenticeHall Inc, New Jersey.

Ryan, L., \& Macky K.A. 1998. Downsizing organizations: Uses, outcomes and strategies. Asia Pacific Journal of Human Resources, 36 (2): 29-45.

Silverman, D. 1997. Qualitative Research Sage, Thousand Oaks, California.

Stake, R.E. 1994. Case studies in Handbook of Qualitative Research, eds N.K. Denzin, \& Y.S. 
Lincoln, Sage, Thousand Oaks, California: 236-247.

Thornhill, A., \& Saunders, M.N.K. 1998. The meanings, consequences and implications of the management of downsizing and redundancy: a review. MCB Personnel Review, 27 (4).

Yin, R.K. 1994. Case Study Research: Design and Methods $2{ }^{\text {nd }}$ Edition Sage, Thousand Oaks, California.

Yin, R.K. 2003. Case Study Research: Design and Methods $3^{\text {rd }}$ Edition Sage, Thousand Oaks, California. 